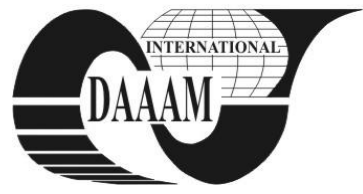

\title{
ASSESSMENT OF ECO DESIGN POTENTIAL OF ELECTRICAL AND ELECTRONIC EQUIPMENTS PRODUCERS
}

\author{
CIOCOIU, C[armen] N[adia]; BANACU, C[ristian] S[ilviu] \& TARTIU, V[alentina] E[lena]
}

\begin{abstract}
This paper presents the Analytical Hierarchy Process (AHP) as a decision making tool for the evaluation of the potential to introduce eco design of Romanian producers from electrical and electronic equipments (EEE) field. The proposed model is based on the analysis of 4 groups of criteria (socioeconomical, technical, legislative and company characteristics) that may affect a successful implementation of eco design.

Key words: eco design, analytical hierarchy process, electrical and electronic equipment producers
\end{abstract}

\section{INTRODUCTION}

Currently the global market for EEE is facing a rapid expansion, due to the high rate of technological changes and the increasing reliance on ICT in every area of human life. As consequence, the waste electrical and electronic equipments (WEEE) represent the category of municipal waste with the fastest growth rate of the quantities generated (Ciocoiu et al, 2010). One of the solutions to improve the management of the obsolete EEE is the ecodesign.The decision to implement the ecodesign is a difficult one because is based on a lot of criteria. This issue was tackled by many papers Borchardt et al (2009), Choi et al. (2008), Persson, J.G. (2006), Veveris M. (2004). Therefore, our paper aims to use the AHP approach to assess the potential of Romanian companies from the EEE sector to introduce ecodesign.

\section{CRITERIA AFFECTING IMPLEMENTATION OF ECODESIGN IN EEE COMPANIES}

Growing environmental concerns, coupled with stricter regulations, the market demand for eco-efficient products and public pressure are fundamentally impacting the way companies design and launch new products worldwide. (Choi et al., 2008). Thus 18 criteria were selected and categorized in four groups (Figure 1). A briefly description of the four groups is presented below.

\subsection{Socio - economical criteria}

Once a company that is leader of a specific sector in the market has more chances to redesign its products, the other companies can consider ecodesign as an opportunity to increase their market share (Borchardt et al., 2009).

In Romania there are companies from EEE sector that are displaying ecodesign and eco-efficiency characteristics of their products and processes through media channels. These actions contribute to the brand image improvement and company's prestige. Also, Romanian consumers are encouraged to replace the old models of cars and electrical appliances with less energy consuming ones, through different types of programs (RABLA, Buy-Back etc).

Ecodesign has a major role in reconfiguration the relationships within the supply chain across Europe as the ecoefficient products are increasingly preferred. The main reasons refer to: the need for specific materials, raw or recycled, that fulfil the ecodesign requirements, the proximity of purchasing places, trade regulations, eco-standards and green taxes.
There is an organic and synergic link between product ecodesign and product Life Cycle Analysis (LCA) defined by the Eco-Labelling Schemes. Good steps have been done since early 90's by emitting LCA Standards as ISO 14031-ISO 14042 series and EU Directives based on LCA research for various products. However, in Romania, despite the fact that some Research Universities and the Romanian Association for Standards (ASRO) have underlined the importance of LCA and eco-labels schemes since the early 90's, only few steps have been done towards ecodesign practices, being still enough room for further improvement.

\subsection{Technical criteria}

Extension of the life span means prolonging the useful life of the EEE without neglecting the changing needs of the consumers. Extending the life span of EEE products can open up markets for new environmental friendly designed products, giving thus EEE producers opportunities for increased sales.

Both materials consumption and energy consumption can be minimised through process design. One noteworthy fact refers to the energy consumption that has already become a marketing tool for producers of home appliances such as refrigerators or washing machines.

Currently EEE contain a significant number of hazardous substances, for instance: lead, cadmium, mercury, chromium and so forth. The ROHS Directive 2002/95/EC prohibits the placing on the EU market of new EEE containing more than agreed levels of lead, cadmium, mercury, chromium, PBB and PBDE flame retardants (European Union, 2003).

At the end of life EEE can be regarded as a resource of: valuable metals (copper, aluminium, silver, and gold), iron, steel, glass, plastic, cardboard, rubber and so on. By adopting the ecodesign principles the EEE producers can enhance recycling by making the product easy to disassemble, providing material identification, simplifying and consolidating the product parts, providing an opportunity for material selection and compatibility checking (NTUA, 2007, p.22).

According to the WEEE directive, EEE producers are responsible for the end of life management of their products. The adoption of the ecodesign principles can enable producers to minimize waste electrical and electronic equipments during the all product life cycle phases.

\subsection{Legislative criteria}

Currently a series of EU directives (WEEE, RoHs, and $\mathrm{EuP})$ in force highlights an increasing need to design and build EEE in an environmentally conscious way. The triangle formed by the EuP, RoHS and WEEE Directives represents a framework for addressing the impacts of EEE throughout their life cycle.

Eco-labeling and certification of EEE have become important parameters in a product strategy, especially in international trade. In addition, implementation on voluntary basis of eco-labels or certification programs can enables EEE producers to target specific segments of consumers, gaining thus a competitive advantage. 


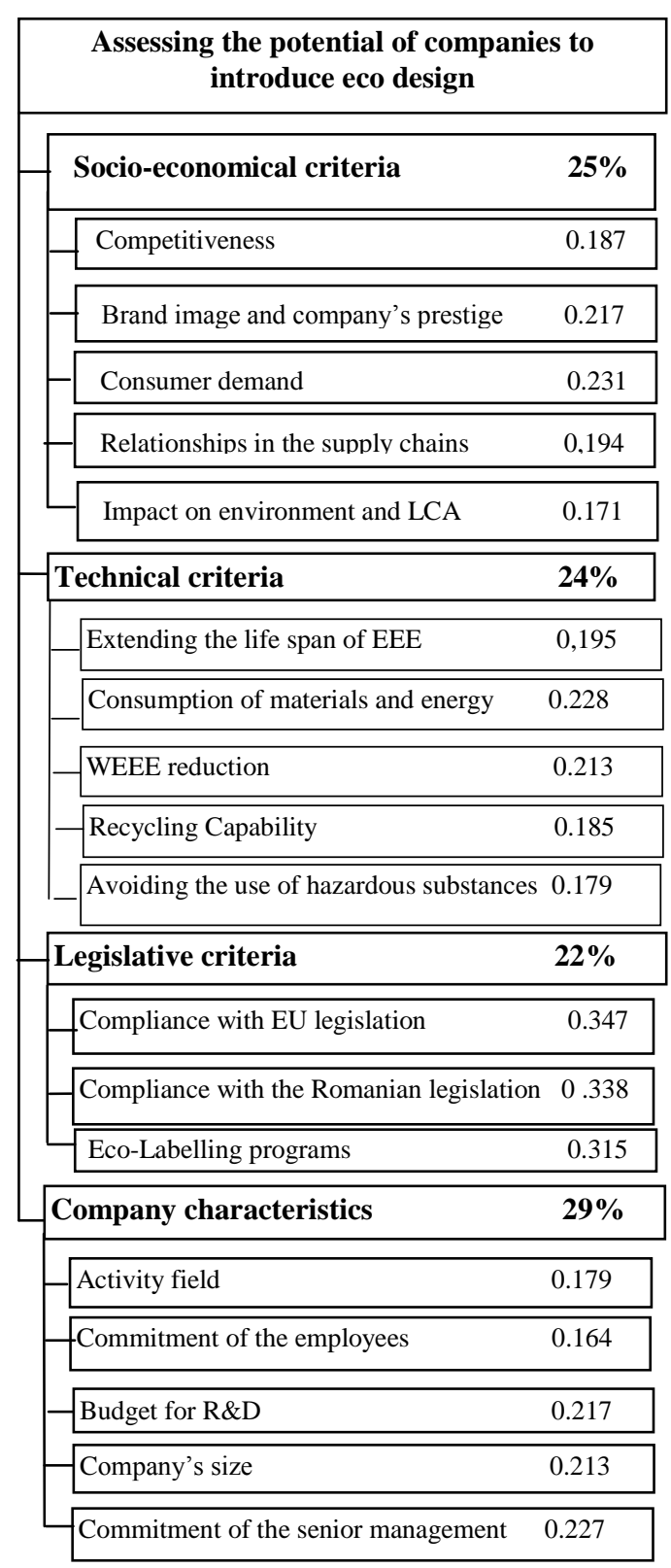

Fig.1. The structure of the model and the weight of each criterion

\subsection{Company characteristics}

The criteria that have been taken into account were: company's size, activity field, commitment of the senior management, commitment of the employees, the budget for $\mathrm{R} \& \mathrm{D}$ in eco-design and innovation.

\section{RESEARCH METHODOLOGY}

The aim of the model is to build a tool to help decision makers from the EEE companies in the assessment phase of ecodesign implementation projects. Taking into account the criteria presented in the previous chapter, was designed the structure of the model and then was calculated the weight of each criterion using AHP method. Pair wise comparison between criteria was made using a scoring scale adapted from Saaty. The successive comparisons have enabled the construction of the matrix of relative importance of criteria. After normalization the weight of each criterion was calculated. The AHP algorithm was applied at each level in the criteria tree. Seven experts from companies, EEE producers associations, universities have done the evaluation of the criteria. The values calculated for the weight of each criterion is shown in Figure 1.

\section{RESULTS}

The AHP analysis led to the following ranking of the evaluation criteria: company characteristics (29\%), socioeconomical (25\%), technical (24\%) and legislative (22\%). The proposed model can help the decision makers to gain a deeper understanding of the key factors involved in the implementation of ecodesign in the EEE companies. In addition, allowed the experts to get an insight on the necessary framework for the integration of different aspects toward sustainable electrical and electronic equipment development.

\section{CONCLUSIONS}

Although the AHP provides a clear rationale with respect to ecodesign implementation in Romanian EEE companies, the main limitation that should be kept in mind when interpreting the findings of this paper refers to the fact that the resultant ranking of criteria cannot be tested for statistical significance and some of the criteria considered are available only for EEE sector. Future research will be carried out on the relation between the eco-efficiency, ecodesign, LCA, LCC and ecolabelling system implementation in Romania. The next step will be the development of ecodesign assessment indicators.

\section{ACKNOWLEDGEMENTS}

This work was supported by CNCSIS -UEFISCDI, project number PNII - IDEI 1834/2008.

\section{REFERENCES}

Borchardt, M.; Pereira, G.M. \& Sellitto M.A. (2009). The assessment of ecodesign applications using the Analytic Hierarchy Process: a case study in three furniture companies, Available from:

http://www.aidic.it/pres09/webpapers/28Borchardt.pdf, Accessed: 2010, October, 3

Ciocoiu N.; Burcea S. \& Tartiu V. (2010). The WEEE management system in Romania. Dimension, Strengths and weaknesses, Theoretical and Empirical Researches in Urban Management, Number 6(15) / May 2010, pp. 5-22, ISSN 2065-3913

Choi, J. K.; Nies, L. F. \& Ramani, K. (2008). A Framework for the Integration of Environmental and Business Aspects Toward Sustainable Product Development. Journal of Engineering Design, Volume 19, Issue 5 October 2008, pp. 431 - 446, ISSN 0954-4828

NTUA (2007). Manual on Eco-Design and End-of-Life management of Electronic Products, Available from: $\mathrm{http} / / /$ ec.europa.eu/environment/life/project/Projects/index.c fm?fuseaction=home.showFile\&rep=file\&fil=IPP_TEL_M anual.pdf, Accessed: 2011, August, 25

Persson, J.G.( 2006). Current trends in product development, 5th International DAAAM Baltic Conference "Industrial engineering -Adding innovation capacity of labour force and entrepreneurs", 20-22 April 2006, Tallinn, Estonia, Available from:

http://innomet.ttu.ee/daaam06/proceedings/05KeyNote.pdf, Accessed: 2010, September, 12

Veveris, M (2004). Design for obsolescence and ecodesign -a dichotomy or an innovation opportunity ?, 4th International DAAAM Conference " Industrial Engineering - Innovation as competitive edge for SME", 29 - 30th April 2004, Tallinn, Estonia, Available from: http://innomet.ttu.ee/daaam04/proceedings/Design\%20Engi neering/Veveris.pdf, Accessed: 2010, September, 20

*** (2003). EU RoHS Directive 2002/95/EC, Available from: http://eurlex.europa.eu/LexUriServ/LexUriServ.do?uri=CE LEX:32002L0095:en:HTML, Accessed: 2008, March, 20 